\title{
Investigation of Psycho-Social Variables Affecting the Professional Life of Persons after the Coaching Education
}

\section{Seckin Doganer ${ }^{1}$ Halil Erdem Akoglu ${ }^{2}$}

'Ankara University, Sports Sciences Faculty, Department of Sports Management, Ankara, Turkey.

Email:heakoglu@ankara.edu.tr.Tel:+905384090553

\section{Abstract}

The aim of this research is to examine the effects of the coaches' emotional labor behavior on emotional burnout and turnover intention. The research group consists of 201 coaches actively working in various sports centers in Ankara province. Personal information form consisting of demographic questions, "Emotional Labor Scale", "Burnout Scale" and "Turnover Intention Scale" were used as data collection tools. In the research, after the normality test; Spearman Correlation and Multiple Regression analysis were performed on the data. The demographic information of the group participating in the study is given as a percentage table. According to the findings, as the knowledge and skill of the coach increases, emotional burnout, surface acting and turnover intention show decrease. At the same time, the increase of Professional success of the coaches causes emotional burnout, desensitization, surface acting and the turnover intention. It has been observed that the role of coaches, whose professional achievements have increased, has increased natural acting levels, but it has been determined that the role of deep acting has no effect on the turnover intention. As a conclusion, it was observed that burnout and turnover intention may decrease as the level of knowledge and skill increases in coaches. In addition, it was determined that surface acting behavior was not preferred by experienced coaches and mostly natural emotions were used.

Citation | Seckin Doganer; Halil Erdem Akoglu (2020) Investigation of Psycho-Social Variables Affecting the Professional Life of Persons after the Coaching Education. Asian Journal of Education and Training, 6(3): 527-535.

\section{History:}

Received: 3 June 2020

Revised: 6 July 2020

Accepted: 10 August 2020

Published: 1 September 2020

Licensed: This work is licensed under a Creative Commons

Attribution 3.0 License (cc) E E

Publisher: Asian Online Journal Publishing Group
Acknowledgement: Both authors contributed to the conception and design of the study.

Funding: This study received no specific financial support

Competing Interests: The authors declare that they have no conflict of interests.

Trans. Transparency: The authors confirm that the manuscript is an honest,
accurate, and transparent account of the study was reported; that no vital features of the study have been omitted; and that any discrepancies from the study as planned have been explained.

Ethical: This study follows all ethical practices during writing.

\section{Contents}

1. Introduction

2. Method ..

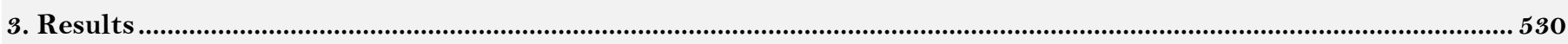

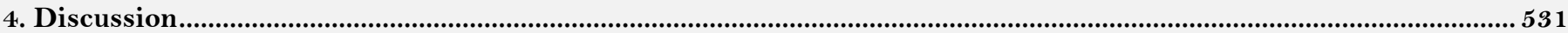

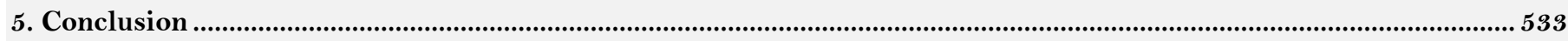

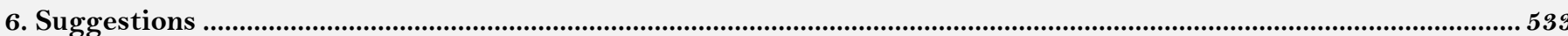

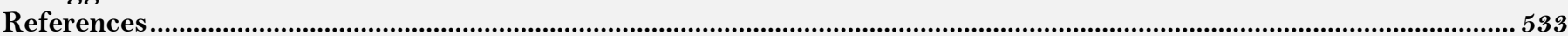




\section{Contribution of this paper to the literature}

This study contributes to the existing literature by examining the effects of the coaches' emotional labor behavior on emotional burnout and turnover intention.

\section{Introduction}

Today, the emotions of the employees and the management of these emotions play a key role for the enterprises in all sectors in the business world. For this reason, employee emotion management has become the focus of researchers especially in the last decade (Lee \& Chelladurai, 2018). When the literature on the subject in analyzed, it is seen that although the researches in sports management are mostly evaluated in terms of customers, recent researches also focus on issues such as employee performance, behavior and burnout (Fletcher \& Scott, 2010; Lee \& Chelladurai, 2018). Along with globalization, one of the most important factors that bring success in the service environment, especially with the increase in the number of enterprises, is that the employees act in a way that meets their current goals and meets the expected performance. In this sense, the most important distinguishing feature is; that employees show superior performance characteristics, that is, they have a "contextual performance” perception (Yürür \& Ünlü, 2011). At this point, although the behavior of the employees towards the customers is very important for the customer and the enterprise, when viewed from the perspective of the employee, it is seen as a situation that may have to exhibit undesirable behaviors and as a result may lead to burnout.

\subsection{Emotional Labor Concept}

The concept of emotional labor was first expressed in Hochschild's book "The Managed Heart", and in the following years, various researchers related to emotional labor introduced new approaches. These approaches are Ashforth \& Humphrey, Hochschild, Morris \& Feldman and as a last Grandey (Balcı, Erdeveciler, \& Altınsoy, 2019). Emotional labor concept (Hochschild, 1983) which is defined as managing and changing internal emotions during the fulfillment of duties for the employee, can create unwanted emotions and stress factors in the staff (Lee, Chelladurai, \& Kim, 2015). Hochschild (1983) defined the concept of emotional labor as "managing emotions for a certain wage". Later, Ashforth and Humphrey (1993) explained the concept of emotional labor as "displaying the right emotions". Morris and Feldman (1996) on the other hand, stated that "effort, planning and control required to express the desired emotion organizationally during interpersonal relations". Finally, Grandey (2000) defined it as both regulating and managing emotions in order to be effective in the business environment. These definitions include organizational expectations of employees' interactions with customers and the state of internal tension or conflict that arises when employees need to display false emotions known as emotional dissonance (Jeung, Kim, \& Chang, 2018). Emotional labor occurs in a variety of professions that require both directly face-to-face contact and a state of emotion (for example, anger or kindness) to those with whom they are in contact (Hochschild, 1983). Grandey and Gabriel (2015) one of the researchers interested in this subject; they have developed a comprehensive emotional labor model consisting of premises, results and moderators. Grandey and Gabriel (2015) stated that emotional labor emerged as a function of the emotional needs of current situation, the individual's inner emotion regulation process and its observable emotional performance When individuals recognize appropriate emotions (i.e. emotional needs), they perform internal emotional regulation strategies to change (i.e. emotional regulation) and then to express those emotions (i.e. emotional performance) (Lee \& Chelladurai, 2018). It can be said that these three components are intertwined to formulate the dynamic and mutual process of emotional labor (Grandey, 2000). Organizations define "codes of conduct" that contain standards that enable employees to reflect the right feeling to their customers (Yürür \& Ünlü, 2011). These behavioral rules are the rules for keeping negative behaviors while waiting for employees to display positive behaviors to suit their business objectives (Augustine \& Joseph, 2008).

Hochschild (1983) considered emotional labor in a two-dimensional structure as surface acting and deep acting behavior, but Ashforth and Humphrey (1993) also added natural behavior to these dimensions. In subsequent research, researchers dealt with emotional labor with a structure inherent in natural behavior (Ashforth \& Humphrey, 1993; Diefendorff, Croyle, \& Gosserand, 2005; Grandey, 2000; Hochschild, 1983). Surface acting is the process of changing the expressions (for example smiling) that the employee encountering a customer or consumer reflects to the customer without changing their inner feelings. In the surface acting behavior, the false emotions occur by suppressing the real emotions of the employee and dictating the business rules (Chu \& Murrmann, 2009; Lee \& Chelladurai, 2018). It is stated that, by applying the model of Fletcher and Scott (2010) a coach who could not enter the cognitive assessment stages while encountering stress exhibits a role-playing behavior on the surface. In the role of deep acting, the employee is trying to transform his personal feelings into the desired emotions, that is, he should act. Behavior in this context arises in the effort of the employee to experience the emotion specified according to the situation. For example, after a defeat, coaches perform deep acting when they try to calm their nerves by reassessing the situation as a challenge rather than threats or harm (Lee \& Chelladurai, 2018). Therefore, surface acting behavior is related to observable expressions, and deep acting behavior is related to changes in internal emotions to meet institutional expectations (Grandey, 2000). According to Rafaeli and Sutton (1989) the situation in deep acting behavior is a benign act, while the situation in surface acting behavior is a malicious approach. Because the surface acting behavior characterizes the observer as an act of deception for the interests of the institution in case of exhibiting the behavior. Diefendorff et al. (2005) defined the third category of emotional labor (natural behavior) as the process of experiencing one's spontaneous emotions without effort. For example, it has been seen that coaches who naturally feel and display enthusiasm during the practice show natural behaviors (Lee \& Chelladurai, 2018). While the studies in the literature on the subject suggest that emotional labor will have negative results, some also state that it may have positive results. Researchers who are concerned with the negative consequences of emotional labor often relate to burnout and job dissatisfaction (Abraham, 1998; Aziz, Widis, \& Wuensch, 2018; Baker, Chu, \& Murrmann, 2012; Grandey, 2000; Hochschild, 1983; Kim, 2008; Lee \& Chelladurai, 2018; Lee, 2019; Morris \& Feldman, 1996; Noh, 2017; Wharton, 1993). Emotional labor can form an important psychological structure within sports organizations. This structure has the potential to shed light on establishing 
an effective coping strategy that allows them to improve individual outcomes (e.g. stress and health) and organizational outcomes (e.g. athletes and team performance) (Lee \& Chelladurai, 2016). In the context of sports, some professions require employees to interact directly with other individuals. For example, personal coaches must use emotional labor to interact with customers in fitness centers (Lee et al., 2015). It is known that the coaches in the service sectors of the sports field consciously display emotions suitable for the business purpose when they encounter emotionally different events in their interactions with customers and followers for a fee. Contrary to this is likely to be considered as a reason for businesses to dismiss them (Ashforth \& Humphrey, 1993). When the literature is examined, studies involving emotion management for individual well-being are included in sports organizations (Wagstaff, Fletcher, \& Hanton, 2012; Wagstaff., Fletcher, \& Hanton, 2012) especially in recent years, research involving the emotional behavior of coaches has been focused on Fletcher and Arnold (2015); Lee et al. (2015); Lee and Chelladurai (2016); Lee and Chelladurai (2018).

\subsection{Emotional Labor and Burnout}

Maslach, Jackson, and Leiter (1996) defined burnout as "emotional exhaustion, depersonalization and personal accomplishment”. Coaches who are exposed to high demands related to work for a certain period of time appear to be emotionally exhausted, and this may cause the coach to become insensitive and personal accomplishment (i.e. a decrease in one's sense of ability and productivity) (Lee \& Chelladurai, 2018). Such experiences have been found to have significant effects on team performance and coaches' health and well-being (McNeill, Durand-Bush, \& Lemyre, 2017). Many studies have consistently shown that different aspects of emotional labor affect individuals' burnout differently (Aziz et al., 2018; Larner, Wagstaff, Thelwell, \& Corbett, 2017; Lee \& Chelladurai, 2018; Lee \& Ji, 2018; Lee, 2019; Tolukan, 2019).

The surface acting, which includes the process of suppressing unpleasant and unwanted emotions and displaying different emotions, creates emotional mismatch in the person and reveals the feeling of originality. There is no emotional incoherence in the deep acting, since the inner feelings are changed before they appear. Finally, natural emotions are negatively associated with coach burnout, because the process does not need to produce any emotional dissonance and psychological effort (Grandey \& Gabriel, 2015). In line with this information, the following hypotheses have been developed:

H1: There is a positive relationship between coaches' feelings of surface acting and emotions of burnout.

H2: There is a negative relationship between coaches' deep acting emotions and emotions of burnout. H3: There is a negative relationship between coaches' natural emotions and emotions of burnout.

\subsection{Emotional Labor and Turnover Intention}

Rusbult, Farrell, Rogers, and Mainous III (1988) see their turnover intention as disruptive and active actions that employees take if they are not satisfied with their job conditions. The theoretical background of the relationship between emotional labor and turnover intention is emotional dissonance theory and research (Chu \& Murrmann, 2009; Cote \& Morgan, 2002). According to the emotional dissonance theory, the difference between the emotional representation that the organization expects from the employees and the emotional representation that the employees show as they come from causes an emotional dissonance and affects the employee (Kruml \& Geddes, 2000; Morris \& Feldman, 1996). It is considered that the increase in this difference may have negative consequences such as dissatisfaction in the employee, creating dissatisfaction within the organization and among colleagues, low performance of work and the intention to quit (Grandey, 2003). Based on this point, the following hypotheses have been developed by making use of previous researches and theories related to the subject:

H4: There is a positive relationship between coaches' surface acting emotions and turnover intention.

H5: There is a negative relationship between coaches' deep acting emotions and turnover intention.

H6: There is a negative relationship between coaches' the natural emotions and turnover intention.

\subsection{Burnout and Turnover Intention}

As mentioned in many studies, a negative result of burnout is the increased risk of leaving work (Kilo \& Hassmén, 2016; Kubayi, 2018). Many coaches who graduated from sports science departments in our country can find themselves in a limited number of work areas. For this reason, it is important to find out the factors that may reduce the intention of the coaches to quit. Among a number of factors leading to the turnover intention, coach burnout has been found to play an important role (Kilo \& Hassmén, 2016; Raedeke, 2004). In this context, the following hypothesis has been developed:

H7: There is a positive relationship between coaches' burnout and turnover intention.

\section{Method}

In this study, in which the quantitative research model was adopted, the correlational survey model was used. The purpose of screening research is to make a description by taking a picture of the current situation related to the research subject (Büyüköztürk, Kılıç Çakmak, Akgün, Karadeniz, \& Demirel, 2017).

\subsection{Research Group}

While creating the group, convenience sampling method, which is non-random sampling methods, is used. Convenience sampling method is a non-random sampling method in which the sample segment chosen from the main mass is determined by the researcher's judgments. In convenience sampling, the data are collected from the main mass in the easiest, fastest and most economical way (Etikan, Alkassim, \& Abubakar, 2016). The study group of the study consisted of 201 ( $n=104$ men and $n=97$ women) working in private sports centers in Ankara. The findings related to descriptive statistics are given in Table 1. 
Table-1. Percentage Distribution of Participants' Demographic Information.

\begin{tabular}{|c|c|c|c|c|c|c|c|c|}
\hline Variable & Group & f & $\%$ & Total & $\overline{\mathbf{x}}$ & $\mathbf{S}$ & Min. & Max. \\
\hline Gender & $\begin{array}{l}\text { Women } \\
\text { Men }\end{array}$ & $\begin{array}{c}97 \\
104\end{array}$ & $\begin{array}{l}48,3 \\
51,7\end{array}$ & 201 & & & & \\
\hline Education Level & $\begin{array}{l}\text { High School } \\
\text { University } \\
\text { Graduate } \\
\end{array}$ & $\begin{array}{c}9 \\
175 \\
17 \\
\end{array}$ & $\begin{array}{c}4,5 \\
87,1 \\
8,5 \\
\end{array}$ & 201 & & & & \\
\hline $\begin{array}{l}\text { Working Hours } \\
\text { Satisfaction }\end{array}$ & $\begin{array}{l}\text { Yes } \\
\text { No }\end{array}$ & $\begin{array}{c}145 \\
56 \\
\end{array}$ & $\begin{array}{l}72,1 \\
27,9 \\
\end{array}$ & 201 & & & & \\
\hline \multicolumn{2}{|l|}{ Age } & & & 201 & 25,34 & 5,14 & 18.00 & 56.00 \\
\hline \multicolumn{2}{|c|}{ Service Year in the Profession (Month) } & & & 201 & 54,37 & 53,37 & 2 & 384 \\
\hline \multicolumn{2}{|c|}{ Average Monthly Income } & & & 201 & 2377,47 & 1331,54 & 250 & 7000 \\
\hline \multicolumn{2}{|c|}{ Coaching Knowledge-Skill Level } & & & 201 & 7,24 & 1,66 & 1,00 & 10,00 \\
\hline \multicolumn{2}{|c|}{ Success in Profession } & & & 201 & 7,48 & 1,52 & 3,00 & 10,00 \\
\hline
\end{tabular}

Note: Frequency (f).

\subsection{Data Collection Tool}

As a data collection tool, first of all, the personal information form containing the demographic information of the participants was applied to the participants, and secondly, "Emotional Labor Scale", "Maslach Burnout Inventory" and "The Turnover Intention Scale" were used. The collected data were analyzed with SPSS 24 program.

Personal Information Form: This section contains 9 items related to the personal information of the participants. These variables are; age, gender, education level, year of service, branch, working hours satisfaction, coaching knowledge skills and success in the profession.

Emotional Labor Scale: The "Emotional Labor Scale", which was developed to determine the emotional labor behavior of the employees, was created by adapting and developing some items of emotional labor scales by Grandey (2003) and Kruml and Geddes (2000). The scale, consisting of 13 items in total, includes three dimensions: surface acting, deep acting and natural emotions. The participants evaluated the scale items with the help of the five Likert Scale $(1=$ Never, 5 = Always $)$.

Maslach Burnout Inventory: Maslach Burnout Inventory was developed by Maslach and Jackson (1981) and Turkish adaptation studies were done by Ergin (1992). The scale, consisting of a total of 22 items, evaluates burnout in three sub-dimensions: Emotional Exhaustion, Depersonalization and Personal Accomplishment.

The Turnover Intention scale: The 3-item turnover intention scale developed by Cammann (1983) and included in the study by Mimaroğlu (2008) was used to measure the turnover intention.

Collection of Data: The scale questions were applied in the form of one-on-one questions and answers, during the data collection phase. The individuals who participated in the study were informed by the researcher about the importance of the study and their importance for this study, and in this context, it was stated that the fact that they gave correct and reflecting answers to the current situation would affect the reality of the research. For this reason, it was assumed that the individuals participating in the research responded realistically to the scale applied.215 of 450 distributed questionnaires were collected. 14 of these surveys, which were analyzed, were not evaluated because they were filled in incorrectly or incompletely by the surveyors. As a result, 201 questionnaires were accepted as valid and evaluated.

\subsection{Data Analysis}

In order to test whether the obtained data shows normal distribution, skewness and kurtosis analyzes were applied and it was understood that the data showed normal distribution as a result of these tests. In the normality distribution measurements, when skewness values are between $-\mathcal{2}$ and +2 and kurtosis values are between -2 and +2 , then the data is identified as normally distributed (George \& Mallery, 2010). Spearman Correlation and Multiple Regression Analysis were applied on the normally distributed data. The normality data and Cronbach's Alpha reliability coefficients of the scale were investigated and given in Table 2.

Table-2. Skewness - Kurtosis values and internal consistency coefficients of the scales

\begin{tabular}{l|l|c|c|c|c}
\hline Scales & Sub Dimensions & Items & Skewness & Kurtosis & $\boldsymbol{\alpha}$ \\
\hline \multirow{4}{*}{ Burnout } & Emotional Exhaustion & 9 &, 175 &,- 358 &, 87 \\
\cline { 2 - 6 } & Desensitization & 5 &, 291 &,- 309 &, 75 \\
\cline { 2 - 6 } & Personal Accomplishment & 8 &,- 603 &, 602 &, 80 \\
\hline \multirow{4}{*}{ Emotional Labor } & Surface Acting & 6 &, 187 &,- 754 &, 90 \\
\cline { 2 - 6 } & Deep Acting & 4 &,- 452 &, 085 &, 81 \\
\cline { 2 - 6 } & Natural Emotions & 3 &,- 470 &,- 299 &, 80 \\
\hline Turnover Intention & Turnover Intention &, 511 &,- 943 &, 93 \\
\hline \multirow{2}{*}{ Note: Skewness is acceptable for -2/+2, Kurtosis is acceptable for -2/+2. } & &
\end{tabular}

\section{Results}

In Table 3, the correlation analysis results of the scales were given. According to the findings, there is a statistically low negative correlation between the coaches' knowledge and skill level and emotional burnout, surface acting and turnover intention. As the coaches' knowledge and skills increase, his emotional burnout and surface acting and turnover intention decrease. There is a statistically negative, low and medium level relationship between the professional success of the coach and emotional burnout, desensitization, surface acting and turnover intention. As the professional success of the coaches increases, their emotional burnout, depersonalization, surface acting and turnover intention decrease. There was a statistically low level of positive correlation between 
professional success, personal accomplishment and natural acting sub-dimensions. As the professional achievements of the coaches increase, personal accomplishment and their natural acting also increase.

Table-3. Correlation analysis results related to the scales.

\begin{tabular}{|c|c|c|c|c|c|c|c|c|c|}
\hline $\begin{array}{l}\text { Sub } \\
\text { Dimensions }\end{array}$ & 1 & 2 & 3 & 4 & 5 & 6 & 7 & 8 & 9 \\
\hline 1-CKS & 1 & & & & & & & & \\
\hline 2-CPS & $0,794 * *$ & 1 & & & & & & & \\
\hline $3-\mathrm{SA}$ & $-0,190^{* * *}$ & $-\mathrm{O}, 189^{* *}$ & 1 & & & & & & \\
\hline 4-DA & $-0,101$ & $-0,046$ & $0,210 * *$ & 1 & & & & & \\
\hline $5-\mathrm{NE}$ & 0,100 & $0,15 \mathrm{O}^{*}$ & $-0,368 * *$ & $0,168^{*}$ & 1 & & & & \\
\hline 6-EE & $-0,219^{* *}$ & $-0,226^{* *} *$ & $0,560 * *$ & 0,081 & $-0,296 * *$ & 1 & & & \\
\hline $7-\mathrm{D}$ & $-0,071$ & $-0,205^{*} *$ & $0,410^{* * *}$ & 0,027 & $-0,300 * *$ & o,668*** & 1 & & \\
\hline 8-PA & 0,102 & $0,185^{* * *}$ & $-0,109$ & $0,240^{* * *}$ & $0,389 * *$ & $-0,183^{*} *$ & $-0,387^{*} *$ & 1 & \\
\hline 9-TI & $-0,358 * *$ & $-0,405^{*} *$ & $0,401 * *$ & 0,0708 & $-0,369 * *$ & 0,567 *** & $0,275^{* *}$ & $-0,161^{*}$ & 1 \\
\hline
\end{tabular}

Note: ${ }^{*} \mathrm{p}<0.05 ;{ }^{* *} \mathrm{p}<0.01$; CKS: coach knowledge-skill; CPS: coach professional success; SA: surfa

There is a statistically positive moderate relationship between the emotional exhaustion levels of the coaches' and their depersonalization, surface acting and turnover intention. As the coaches' emotional exhaustion increases, their depersonalization, surface acting and turnover intentions also increase. There is a statistically low negative correlation between emotional exhaustion and personal success and natural emotions. As emotional exhaustion increases, personal sense of accomplishment and natural emotions decrease in the coach.

Table-4. The effect of emotional labor and burnout perception on the turnover intention.

\begin{tabular}{|c|c|c|c|c|c|c|}
\hline \multirow{2}{*}{$\begin{array}{l}\text { Dependent } \\
\text { Variable }\end{array}$} & \multirow[t]{2}{*}{ Independent Variable } & \multicolumn{2}{|c|}{$\begin{array}{l}\text { Non-Standardized } \\
\text { Coefficients }\end{array}$} & \multirow{2}{*}{$\begin{array}{c}\begin{array}{c}\text { Standardized } \\
\text { Coefficients }\end{array} \\
\text { Beta } \\
\end{array}$} & \multirow[t]{2}{*}{$\mathbf{t}$} & \multirow{2}{*}{$\begin{array}{c}\text { Level of } \\
\text { Significance }\end{array}$} \\
\hline & & B & Std. error & & & \\
\hline $\begin{array}{l}\text { Turnover } \\
\text { Intention }\end{array}$ & $\begin{array}{l}\text { (Constant) } \\
\text { Surface } \\
\text { Deep acting } \\
\text { Natural Emotions }\end{array}$ & $\begin{array}{c}2,528 \\
0,345 \\
0,091 \\
-0,356\end{array}$ & $\begin{array}{c}0,472 \\
0,085 \\
0,094 \\
0,91\end{array}$ & $\begin{array}{r}0,286 \\
0,065 \\
-0,275\end{array}$ & $\begin{array}{c}5,361 \\
4,039 \\
0,967 \\
-3,910\end{array}$ & $\begin{array}{l}0,000 \\
0,000 \\
0,335 \\
0,000\end{array}$ \\
\hline $\mathrm{R}=0,470$ & $\mathrm{R}^{2}=0,209 \quad \mathrm{~F}=18,639$ & \multicolumn{5}{|c|}{$\mathrm{p}=\mathrm{O}, 000$} \\
\hline $\begin{array}{l}\text { Turnover } \\
\text { Intention }\end{array}$ & $\begin{array}{l}\text { (Constant) } \\
\text { Emotional Exhaustion } \\
\text { Desensitization } \\
\text { Personal accomplishment }\end{array}$ & $\begin{array}{r}1,407 \\
1,073 \\
-0,154 \\
-0,230\end{array}$ & $\begin{array}{l}0,526 \\
0,117 \\
0,051 \\
0,112\end{array}$ & $\begin{array}{l}0,710 \\
-0,249 \\
-0,128\end{array}$ & $\begin{array}{c}2,674 \\
9,190 \\
-3,023 \\
-2,051\end{array}$ & $\begin{array}{l}0,008 \\
0,000 \\
0,003 \\
0,042\end{array}$ \\
\hline $\mathrm{R}=0,596$ & \multicolumn{6}{|c|}{$\mathrm{R}^{2}=0,346 \quad \mathrm{~F}=36,193 \quad \mathrm{p}=0,000$} \\
\hline
\end{tabular}

Note: $\mathrm{p}<0.000$.

In Table 4, in order to evaluate the power of the Emotional Labor Scale and Burnout Inventory subdimensions, the turnover intention was taken as dependent variable and multiple linear regression analysis was performed. When the table is examined; It was determined that the VO sub-dimensions significantly predicted the turnover intention variable $(\mathrm{p}=0,000)$ and that the independent variables explained the turnover intention at the rate of $18.6 \%(\mathrm{R} 2=0.209)$. Of the independent variables, it was determined that only the deep acting had no significant predictive effect on the dependent variable.

Again, the turnover intention as a dependent variable; As a result of the analysis conducted to evaluate the predictive power of the Burnout Scale sub-dimensions as an independent variable, it is seen that the BS subdimensions explained the intention to quit from work by $36 \%(\mathrm{R} 2=0.346)$. All of the independent variables have a significant predictive effect on turnover intention.

\section{Discussion}

According to the results of the research, a statistically negative and low-level relation was found between the knowledge and skill level of the coach and the emotional burnout, surface acting and turnover intention. This shows that while the $\mathrm{H} 1$ hypothesis is not confirmed, the $\mathrm{H} 4$ hypothesis is not. As the knowledge and skill of the coaches increases, emotional burnout, surface acting and turnover intention decrease. When examining the various emotional states that arise in the business environment, it is necessary to divide the occupational groups into two as occupational groups that require physical labor and emotional labor.

In occupational groups that require emotional labor, such as the coaching profession, it is important that employees have control over their emotions because employees in this group must frequently interact with people around them Grandey and Sayre (2019). Considering that the concept of burnout leads the person to three different negative behaviors such as emotional exhaustion, depersonalization and personal success reduction, it is known that it can direct employees not only to coaches but also to employees to leave their jobs (Brotheridge \& Grandey, 2002). Burnout, on the other hand, can increase the turnover intention by creating low performance in coaches. A study showing that the professional burnout of coaches is related to the sense of job satisfaction, emphasizing that the emotional commitment to the profession in coaches can have positive results for the athlete and the team, suggesting that trainings can be given in different strategies especially for these occupational groups that require emotional labor(Lee et al., 2015). These trainings can help coaches express themselves more comfortably within the team, as well as create positive effects such as reduced sense of burnout and strengthened professional commitment. As a matter of fact, according to a study examining the professional burnout status of coaches, more burnout is observed in coaches taking part in prestigious matches (Hjalm, Kentta, Hassmenan, \& Gustafsson, 2007). However, 
it is possible to see different results when the literature is examined. For example, in a study examining the burnout levels of football coaches, unlike the previous result, it was found that coaches' burnout levels were low, but it was suggested that training-related activities should be carried out to avoid problems such as keeping the motivation of the coaches high and role conflict (Tolukan, 2019). These results are similar to our results regarding emotional burnout, surface acting and turnover intention, with the increased knowledge and skill of coaches.

In the research, it was determined that as the professional success of the coaches increased, their emotional burnout, depersonalization, surface acting and turnover intention were reduced. Considering the relationship of coaches with athletes, it is known that common areas and face-to-face communication are quite intense, both in encounters and training hours. Although it is known that this situation may increase the perception of burnout, it can be thought that the professional experience factor has a preventive effect on this negative effect (Brotheridge \& Grandey, 2002). The coaching profession, which is seen as a highly dynamic and socially relational activity, is known as a profession group that requires skills and experience in many fields including competition, entertainment, social activity, self-esteem development, physical empowerment and education. Therefore, it would not be correct to think that the person who is positioned as a coach only works on improving sports performance (Morgan \& Bush, 2016). In this case, it can be thought that the coaching profession, when combined with the factors in question, has different effects on exhaustion and leaving work. As a matter of fact, in a study examining the relationship between emotional exhaustion between the professional years of the coaches, it was found that more emotional exhaustion was observed in the coaches working between 9-12 years, but in the same research, it was found that this effect started to decrease and the sense of desensitization decreased in the coaches with 17 years or more (Biber, Ersoy, Acet, \& Küçük, 2010). In a study where demographic factors have not been tested, but the relationship of coaches' professional burnout levels with co-workers has been determined, it has been determined that the sense of burnout may decrease over time and there are strong relationships in the perception of burnout for coaches, athletes and other employees (Myhre \& Moen, 2017). In a different study using qualitative method, it was found that coaches who experienced high burnout showed symptoms of fatigue, sleep problems, drowsiness and similar as the season progressed, while coaches who experienced low burnout felt more active in this process with their feelings of being more energetic and cheerful. The research emphasizes that this situation may be related to motivation and experience (Bentzen, Lemyre, \& Kenttä, 2017). These results can be seen as the effects of the professional experience factor and are similar to our research results. It is also important in terms of showing that the motivation phenomenon has direct effects on burnout and turnover intention.

According to the results of the research, as the professional achievements of the coaches increase, personal accomplishment and natural emotions also increase. In a master's thesis research examining the burnout levels of coaches working in private gyms; it was observed that coaches working 11 hours or more experienced more emotional exhaustion than the other group, similar to the research results in the literature. According to the results of the research, it was determined that the personal success feeling levels of the coaches in the group giving private lessons were higher than the coaches in the other group, but there was no significant difference in the sense of burnout (Akl, 2014). The profession of coaching can be seen as a working environment in which sociological perspective will increase as personal success increases and professional success will increase. However, this situation, of course, brings more stress factors. Therefore, coaches may tend to quit their profession, thinking that they may not always maintain their personal sense of accomplishment. Therefore, the desire to move away from an environment that requires high performance constantly suggests to coaches to step back from this tiring environment that requires continuous success (Olusoga \& Kenttä, 2017). It is observed that the stress factor imposes a significant burden on the employees in the institutions where the personal and professional sense of success is desired to be at the top, and they are pressured to protect this performance by their superiors. This situation creates negative situations especially in the form of distress, fatigue and burnout among employees and leads them to behaviors that can lead to quitting the profession (Grant, 2017). In another study on stress factors, emotional labor and burnout, this situation was supported and it was found that the frequency of organizational stress factors increased the sense of burnout for sports activities. The research emphasized the importance of the emotional labor factor between the frequency of organizational stress and burnout based on the results obtained (Larner et al., 2017). Frequent and chronic work stress can provide social support gains in difficult situations within the organization and as a result, it may be thought to have a positive aspect in terms of managing job demands, but this situation cannot prevent burnout (Jeung et al., 2018). These results confirm the H3 and H6 hypotheses, but suggest that the personal accomplishment in coaches may put them into burnout in the future, even if it is considered as a positive process at the beginning.

When the results of the research were examined, it was determined that the role of deep acting in the turnover intention does not make a significant difference on the dependent variable, and the $\mathrm{H} 2$ and $\mathrm{H} 5$ hypotheses were confirmed. When the literature is examined, it is seen that this situation is similar to the result of a research conducted in different occupational groups. According to the research result in question, deeply acting behavior does not have a significant effect on job stress (Celik \& Ylldı, 2016). In a study examining the emotional labor and coach competencies of football coaches in connection with the subject, a positive relationship was found between deep acting behavior and coach competence, and this result was explained as the intention of the coaches to show sincere feelings by emphasizing that it was related to the motivation and character structure of the coaches (Güllü $\&$ Donuk, 2019). Since the concept of emotional labor is known to be a publicly observable face and physical image behavior (Hochschild, 1983) it can be seen that the use of such behaviors by employees is actually positive aspects. Indeed, in a similar study, it was found that the deep acting did not create statistically significant differences on exhaustion or depersonalization and showed positive relationships on job performance and job satisfaction (Humphrey, Ashforth, \& Diefendorff, 2015). These results in the literature confirm the H7 hypothesis and are similar to our research results, but the existence of many factors related to emotional labor and role-playing behavior and the existence of many emotional labor-related factors (Hings, Wagstaff, Anderson, Gilmore, \& Thelwell, 2018) are considered important for the investigation of such relationships in future research. 


\section{Conclusion}

As a result, it was found that, as the knowledge and skill levels of the coaches increased, they were more resistant to negative emotional states such as burnout. Surface acting behavior, which is seen as an artificial phenomenon, decreases with experience and reduces the emotional burnout feeling of the coaches. The duration of coaches' duty is seen as an effect on burnout and leaving the profession. As a matter of fact, as the duration of the profession increases, even if there is a sense of burnout, the effect may decrease with the experience factor. This can be considered important in that it emphasizes the importance of experience in the coaching profession. Professional and personal success can strengthen the emotional state of the coaches and increase their motivation. However, as this situation continues, it has been determined that coaches may experience performance anxiety and as a result they may tend to turnover intention due to this concern.

Emotional labor and deep acting behavior can be considered as a natural process for coaches. Because the coaching profession is an emotional labor-intensive profession by nature, such behaviors suggest that coaches behave naturally in terms of their profession and successfully fulfill the requirements of the profession. The fact that coaches, who interact with many athletes and sportsmen, especially because of large sports organizations, try to overcome such situations successfully, shows that they act as internally as possible while showing emotional labor. These results are important for determining that coaches are experienced in job stress.

It has been observed that coaches use emotional labor behavior very effectively in their professional life and they provide this situation in the balance of motivation and performance. Disruption of this type of balance should be seen as a factor that will increase the intention of leaving the job.

\section{Suggestions}

Coaches try to manage a very crowded social environment consisting of athletes, followers and other sports members. This situation causes coaches who are at the center of all successes and defeats to show a lot of emotional labor. Emotional labor behavior leads coaches to negative situations such as burnout and turnover, when professional difficulties are not managed well. In this case, the working time and performances of the coaches must be reviewed. Coach, who is in constant expectation of success, may experience burnout earlier and turn to profession behavior. This situation should be taken under control with the sports organization managers. Since it is seen that coaches are more successful when their motivation is high, it can be suggested that managers should empathize in the process and try to manage the workload in a balanced way. Increasing the knowledge and skills of coaches is another issue that can decrease the intention to quit. For this reason, increasing the activities in which they can gain training and skills can be positive for coaches. Since the situation in question will increase the sense of personal success, it is thought that it can naturally reduce undesirable conditions such as burnout.

The research was carried out with 201 coaches belonging to private sports centers actively working in Ankara. In future research, this number can be increased and coaches from different provinces can be included in the research. Quantitative method was used in the study and various scales measuring the emotional state of the coaches were analyzed. In future researches, qualitative method can be used and emotional labor and burnout situations can be examined together with coaches of different branches. With this method, since the personal opinions of the coaches can be reached, broader conclusions can be made about the intention to quit and emotional labor.

\section{References}

Abraham, R. (1998). Emotional dissonance in organizations: Antecedents, consequences, and moderators. Genetic, Social, and General Psychology Monographs, 124(2), 229-246.

Akı, C. B. (2014). Comparison of burnout status of coaches working in commercial sports businesses and municipal sports facilities example of fitness businesses in Istanbul and spor as. Master Thesis, Bahçeşehir University Institute of Social Sciences.

Ashforth, B. E., \& Humphrey, R. H. (1993). Emotional labor in service roles: The influence of identity. Academy of Management Review, 18(1), 88-115. Available at: https://doi.org/10.2307/258824.

Augustine, S. K., \& Joseph, B. (2008). Global cases on hospitality industry. In Vinnie Jauhari Phd. (Eds.), Emotional labor among the frontline employees of the hotel industry in India (pp. 22 1-243). London: Routledge Press.

Aziz, S., Widis, A., \& Wuensch, K. (2018). The association between emotional labor and burnout: The moderating role of psychological capital. Occupational Health Science, 2(4), 365-383. Available at: https://doi.org/10.1007/s41542-018-0029-1.

Baker, M. A., Chu, K. H., \& Murrmann, S. K. (2012). When we are onstage, we smile: The effects of emotional labor on employee work outcomes. International Journal of Hospitality Management, 31(3), 906-915. Available at: https://doi.org/10.1016/j.ijhm.2011.10.009.

Balcı, V., Erdeveciler, Ö., \& Altınsoy, Ü. (2019). Akademisyenlerin duygusal emek düzeylerinin incelenmesi. Sportif Bakış: Spor ve Eğitim Bilimleri Dergisi, 6(2), 179-194. Available at: https://doi.org/10.33468/sbsebd.98.

Bentzen, M., Lemyre, N., \& Kenttä, G. (2017). A comparison of high-performance football coaches experiencing high-versus low-burnout symptoms across a season of play: Quality of motivation and recovery matters. International Sport Coaching Journal, 4(2), 133-146. Available at: https://doi.org/10.1123/iscj.2016-0045.

Biber, E., Ersoy, A., Acet, M., \& Küçük, V. (2010). Evaluation of burnout levels of Turkish football coaches. Selcuk University Journal of Physical Education and Sports Science, 12(2), 134-143. Available at: https://doi.org/10.4127/jbe.2010.0031.

Brotheridge, C. M., \& Grandey, A. A. (2002). Emotional labor and burnout: Comparing two perspectives of people work. Journal of Vocational Behavior, 60(1), 17-39. Available at: https://doi.org/10.1006/jvbe.2001.1815.

Büyüköztürk, Ş., Kılıç Çakmak, E., Akgün, Ö. E., Karadeniz, Ş., \& Demirel, F. (2017). Scientific research methods. Ankara: Pegem.

Cammann, C. (1983). Assessing the attitudes and perceptions of organizational members. Assessing Organizational Change: A Guide to Methods, Measures, and Practices, 71-138.

Celik, M., \& Yıldız, B. (2016). The mediating role of stress in the effect of emotional labor level on the intention to quit. Journal of International Social Research, 9(45), 734-745.

Chu, K. H.-L., \& Murrmann, S. K. (2009). Development and validation of the hospitality emotional labor scale. Tourism Management, 27(6), 1181-1191. Available at: https://doi.org/10.1016/j.tourman.2005.12.011.

Cote, S., \& Morgan, L. M. (2002). A longitudinal analysis of the association between emotion regulation, job satisfaction, and intentions to quit. Journal of Organizational Behavior: The International Journal of Industrial, Occupational and Organizational Psychology and Behavior, 23(8), 947-962. Available at: https://doi.org/10.1002/job.174.

Diefendorff, J. M., Croyle, M. H., \& Gosserand, R. H. (2005). The dimensionality and antecedents of emotional labor strategies. Journal of Vocational Behavior, 66(2), 339-357. Available at: https://doi.org/10.1016/j.jvb.2004.02.001. 
Ergin, C. (1992). Adaptation of burnout and maslach burnout inventory in doctors and nurses. Paper presented at the Rüveyde Bayraktar and İhsan Dağ (Ed.), VII. In the Scientific Studies of the National Congress of Psychology (143-154). Ankara: VII. National Psychology Congress Organizing Committee and Turkish Psychological Association.

Etikan, I., Alkassim, R., \& Abubakar, S. (2016). Comparision of snowball sampling and sequential sampling technique. Biometrics and Biostatistics International Journal, 3(1), 55.

Fletcher, D., \& Scott, M. (2010). Psychological stress in sports coaches: A review of concepts, research, and practice. Journal of Sports Sciences, 28(2), 127-137. Available at: https://doi.org/10.1080/02640410903406208.

Fletcher, D., \& Arnold, R. (2015). Performance leadership and management in elite sport: Current status and future directions. In S. Andersen, B. Houlihan, \& L. Ronglan (Eds.), managing elite sport systems: Research and practice. Abingdon: Routledge.

George, D., \& Mallery, M. (2010). SPSS for windows step by step: A simple guide and reference, 17.0 update (10th ed.). Boston: Pearson.

Grandey, A. A. (2003). When "the show must go on: Surface acting and deep acting as determinants of emotional exhaustion and peer-rated service delivery. Academy of Management Journal, 46(1), 86-96. Available at: https://doi.org/10.5465/30040678.

Grandey, A. A., \& Sayre, G. M. (2019). Emotional labor: Regulating emotions for a wage. Current Directions in Psychological Science, 28(2), 131-137. Available at: https://doi.org/10.1177/0963721418812771.

Grandey, A. A., \& Gabriel, A. S. (2015). Emotional labor at a crossroads: Where do we go from here? Annual Review of Organizational Psychology and Organizational Behavior, 2(1), 323-349.

Grandey, A. A. (2000). Emotional regulation in the workplace: A new way to conceptualize emotional labor. Journal of Occupational Health Psychology, 5(1), 95-1 10. Available at: https://doi.org/10.1037/1076-8998.5.1.95.

Grant, A. M. (2017). Solution-focused cognitive-behavioral coaching for sustainable high performance and circumventing stress, fatigue and burnout. Consulting Psychology Journal: Practice and Research, 69(2), 111.

Güllü, S., \& Donuk, B. (2019). Examining the relationship between emotional labor and coach competencies of football coaches. Journal of History School, 12(38), 58-79.

Hings, R. F., Wagstaff, C. R., Anderson, V., Gilmore, S., \& Thelwell, R. C. (2018). Professional challenges in elite sports medicine and science: Composite vignettes of practitioner emotional labor. Psychology of Sport and Exercise, 35, 66-73. Available at: https://doi.org/10.1016/j.psychsport.2017.11.007.

Hjalm, S., Kentta, G., Hassmenan, P., \& Gustafsson, H. (2007). Burnout among elite soccer coaches. Journal of Sport Behavior, 30(4), 415-427. Available at: https://doi.org/10.1037/e548052012-669.

Hochschild, A. R. (1983). The managed heart: Commercialization of human feeling. Berkeley: University of California Press.

Humphrey, R. H., Ashforth, B. E., \& Diefendorff, J. M. (2015). The bright side of emotional labor. Journal of Organizational Behavior, 36(6), 749-769. Available at: https://doi.org/10.1002/job.2019.

Jeung, D.-Y., Kim, C., \& Chang, S.-J. (2018). Emotional labor and burnout: A review of the literature. Yonsei Medical Journal, 59(2), 187-193. Available at: https://doi.org/10.3349/ymj.2018.59.2.187.

Kilo, R. A., \& Hassmén, P. (2016). Burnout and turnover intentions in Australian coaches as related to organisational support and perceived control. International Journal of Sports Science $\mathcal{E}^{2}$ Coaching, 11(2), 151-161. Available at: https://doi.org/10.1177/1747954116636710.

Kim, H. J. (2008). Hotel service providers' emotional labor: The antecedents and effects on burnout. International Journal of Hospitality Management, 27(2), 151-161. Available at: https://doi.org/10.1016/j.ijhm.2007.07.019.

Kruml, S. M., \& Geddes, D. (2000). Exploring the dimensions of emotional labor: The heart of hochschild's work. Management Communication Quarterly, 14(1), 8-49. Available at: https://doi.org/10.1177/0893318900141002.

Kubayi, A. (2018). Burnout and paths to turnover intentions among South African sport coaches. Montenegrin Journal of Sports Science and Medicine, 7(2), 43-47. Available at: https://doi.org/10.26773/mjssm.180907.

Larner, R. J., Wagstaff, C., Thelwell, R., \& Corbett, J. (2017). A multistudy examination of organizational stressors, emotional labor, burnout, and turnover in sport organizations. Scandinavian Journal of Medicine E Science in Sports, 27(12), 2103-2115. Available at: https://doi.org/10.1111/sms.12833.

Lee, Y. H., \& Chelladurai, P. (2018). Emotional intelligence, emotional labor, coach burnout, job satisfaction, and turnover intention in sport leadership. European Sport Management Quarterly, 18(4), 393-412. Available at: https://doi.org/10.1080/16184742.2017.1406971.

Lee, Y. H., Chelladurai, P., \& Kim, Y. (2015). Emotional labor in sports coaching: Development of a model. International Journal of Sports Science \& Coaching, $10(2-3), 561-575$. Available at: https://doi.org/10.1260/1747-9541.10.2-3.561.

Lee, Y. H., \& Chelladurai, P. (2016). Affectivity, emotional labor, emotional exhaustion, and emotional intelligence in coaching. Journal of Applied sport Psychology, 28(2), 170-184. Available at: https://doi.org/10.1080/10413200.2015.1092481.

Lee, E. K., \& Ji, E. J. (2018). The moderating role of leader-member exchange in the relationships between emotional labor and burnout in clinical nurses. Asian Nursing Research, 12(1), 56-61. Available at: https://doi.org/10.1016/j.anr.2018.02.002.

Lee, Y. H. (2019). Emotional labor, teacher burnout, and turnover intention in high-school physical education teaching. European Physical Education Review, 25(1), 236-253. Available at: https://doi.org/10.1177/1356336x17719559.

Maslach, C., \& Jackson, S. E. (1981). The measurement of experienced burnout. Journal of Organizational Behavior, 2(2), 99-113. Available at: https://doi.org/10.1002/job.4030020205.

Maslach, C., Jackson, S., \& Leiter, M. (1996). Maslach burnout inventory manual (3rd ed.). Palo Alto, CA: Consulting Psychologists Press.

McNeill, K., Durand-Bush, N., \& Lemyre, P.-N. (2017). Understanding coach burnout and underlying emotions: A narrative approach. Sports Coaching Review, 6(2), 179-196. Available at: https://doi.org/10.1080/2 1640629.2016.1163008.

Mimaroğlu, H. (2008). The effects of the psychological contract on the attitudes and behaviors of the staff: A research on medical sales representatives, Çukurova University Institute of Social Sciences. Unpublished Doctoral Dissertation, Adana.

Morgan, H. J., \& Bush, A. J. (2016). Sports coach as transformative leader: Arresting school disengagement through community sport-based initiatives. Sport, Education and Society, 21(5), 759-777. Available at: https://doi.org/10.1080/13573322.2014.935319.

Morris, J. A., \& Feldman, D. C. (1996). The dimensions, antecedents, and consequences of emotional labor. Academy of Management Review, 21(4), 986-1010. Available at: https://doi.org/10.2307/259161.

Myhre, K., \& Moen, F. (2017). The effects of the coach-athlete working alliance on affect and burnout among high level coaches. Central European Journal of Sport Sciences and Medicine, 18(2), 41-56. Available at: https://doi.org/10.18276/cej.2017.2-05.

Noh, Y. G. (2017). Influence of social support on the relationship between practice stress, emotional labor and burnout among nursing students. Journal of Korean Academy of Nursing Administration, 23(5), 461-470. Available at: https://doi.org/10.11111/jkana.2017.23.5.461.

Olusoga, P., \& Kenttä, G. (2017). Desperate to quit: A narrative analysis of burnout and recovery in high-performance sports coaching. The Sport Psychologist, 31(3), 237-248. Available at: https://doi.org/10.1123/tsp.2016-0010.

Raedeke, T. D. (2004). Coach commitment and burnout: A one-year follow-up. Journal of Applied Sport Psychology, 16(4), 333-349. Available at: https://doi.org/10.1080/10413200490517995.

Rafaeli, A., \& Sutton, R. I. (1989). The expression of emotion in organizational life. Research in Organizational Behavior, $11(1), 1-42$.

Rusbult, C. E., Farrell, D., Rogers, G., \& Mainous III, A. G. (1988). Impact of exchange variables on exit, voice, loyalty, and neglect: An integrative model of responses to declining job satisfaction. Academy of Management journal, 31(3), 599-627. Available at: https://doi.org/10.5465/256461.

Tolukan, E. (2019). Relationship between emotional labor behavior and burnout level of football coaches. International Journal of Higher Education, 8(2), 7-15. Available at: https://doi.org/10.5430/ijhe.v8n2p7.

Wagstaff, C., Fletcher, D., \& Hanton, S. (2012). Positive organizational psychology in sport: An ethnography of organizational functioning in a national sport organization. Journal of Applied Sport Psychology, 24(1), 26-47. Available at: https://doi.org/10.1080/10413200.2011.589423.

Wagstaff., C. R., Fletcher, D., \& Hanton, S. (2012). Exploring emotion abilities and regulation strategies in sport organizations. Sport, Exercise, and Performance Psychology, 1(4), 268-282. Available at: https://doi.org/10.1037/a0028814. 
Wharton, A. S. (1993). The affective consequences of service work: Managing emotions on the job. Work and Occupations, 20(2), 205-232. Available at: https://doi.org/10.1177/0730888493020002004.

Yürür, S., \& Ünlü, A. G. O. (2011). Emotional labor, emotional exhaustion and the intention to leave work. ISGUC The Journal of Industrial Relations and Human Resources, 13(2), 83-103. 